\title{
Asymmetric catalysis with bifunctional cinchona alkaloid-based urea and thiourea organocatalysts
}

\author{
Stephen J. Connon \\ Received (in Cambridge, UK) 13th December 2007, Accepted 15th January 2008 \\ First published as an Advance Article on the web 21st February 2008 \\ DOI: $10.1039 / b 719249$ e
}

Cinchona alkaloid derivatives modified to include a (thio)urea component have emerged in the last three years as readily accessible, robust and tunable bifunctional organocatalysts for a range of synthetically useful transformations. The origins of these catalysts and the major developments in their application in enantioselective synthesis are reviewed.

\section{Introduction}

The idea of using organic catalysts to promote asymmetric transformations is certainly not a new one, ${ }^{1}$ however after considerable time in the wilderness it has rapidly gained widespread currency among organic chemists over the course of the last decade. ${ }^{2}$ While the general advantages associated with the use of organocatalysts have been set down many times $^{2}$ and will not be reiterated here, it is perhaps worth mentioning that one of the most attractive aspects of organocatalysis is that the biomimetic use of multiple, relatively weak catalyst-substrate interactions (as opposed to single, strong Lewis acid-Lewis base attractions, for example) facilitates the design of so-called bifunctional ${ }^{3}$ catalysts: catalysts which possess (often) complementary functionality capable of activating two components of a chemical reaction simultaneously. Such a strategy - ubiquitous in biocatalytic systems - allows the practitioner to aspire towards unprecedented levels of control over the encounter of reactants in a given transition state, with obvious potential benefits in terms of both reaction rate and (where applicable) stereoselectivity.

Centre for Synthesis and Chemical Biology, School of Chemistry, University of Dublin, Trinity College, Dublin 2, Ireland. E-mail: connons@tcd.ie; Fax: +3531671 2826; Tel: +35318961306

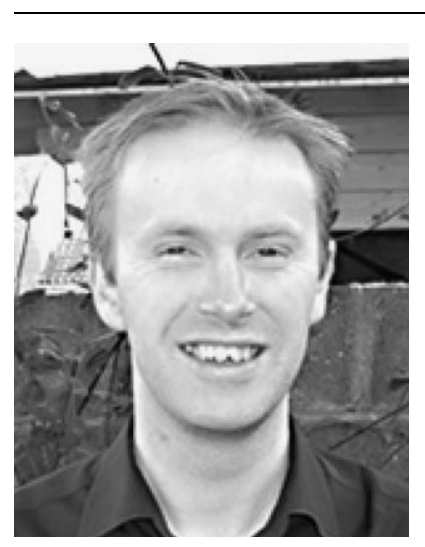

Stephen Connon was born in 1976 and received his $P h D$ from University College Dublin under the supervision of Prof. A. F. Hegarty in 2000. After being awarded an Alexander von Humboldt fellowship he spent two years at the Technische Universität Berlin with Prof. S. Blechert, studying the design of new olefin metathesis catalysis. In 2003 he was appointed to the staff of Trinity College. His research interests include organocatalysis, the discovery and development of novel synthetic methodology and the design of new anti-cancer and anti-bacterial agents.
In 1981, Wynberg and Hiemstra ${ }^{4,5}$ published a landmark paper demonstrating that cinchona alkaloids promote the moderately enantioselective addition of thiophenols to cyclic enones (Scheme 1). ${ }^{6}$ Screening a range of both natural and modified alkaloids allowed the authors to recognise that these catalysts operated bifunctionally in this reaction-catalyst activity and selectivity were dependant on the presence of both a basic tertiary amine moiety (capable of deprotonating the thiol pronucleophile) and a hydrogen-bond donating hydroxy group (which activates the enone electrophile) in a stereochemical arrangement conducive to their cooperation in the reaction transition state. As a conclusion to this study Wynberg predicted:

'The scope of the utility of hydroxy amines can perhaps be extended by constructing a catalyst containing a stronger base or a better hydrogen-bond donor...Perhaps other Michael reactions can then be performed which are not possible with bases like quinine.'

In view of the clear precedent set by Wynberg and the ready availability of cinchona alkaloid derivatives it is somewhat surprising that this field did not undergo immediate rapid growth. At turn of the millenium Hatayekama et al. found that the 'better hydrogen bond donor' can be obtained from demethylation of the $6^{\prime}$-methoxy moiety in conformationally restricted quinine derivatives, ${ }^{7}$ while Deng and co-workers later demonstrated that readily accessible $6^{\prime}$-demethylated quinine/quinidine (and 9-O-arylated derivatives) could serve as more effective promoters of asymmetric Michael addition processes than their parent alkaloids. ${ }^{8}$ No other modifications to the parent alkaloid structure had been shown to lead to improved bifunctional catalysis. ${ }^{9}$

\section{Early studies: the development of (thio)urea- substituted cinchona alkaloid catalysts}

In the early 1990s Curran and $\mathrm{Kuo}^{10}$ developed the urea catalyst 9 for the promotion of the allylation of cyclic $\alpha$-sulfinyl radicals with allyltributylstannane ${ }^{10 a}$ and Claisen rearrangements. ${ }^{10 b}$ The basic concept underpinning the choice of these materials is simple - N, $N^{\prime}$-diaryl (thio)ureas are robust, tunable and readily preparable catalyst templates 

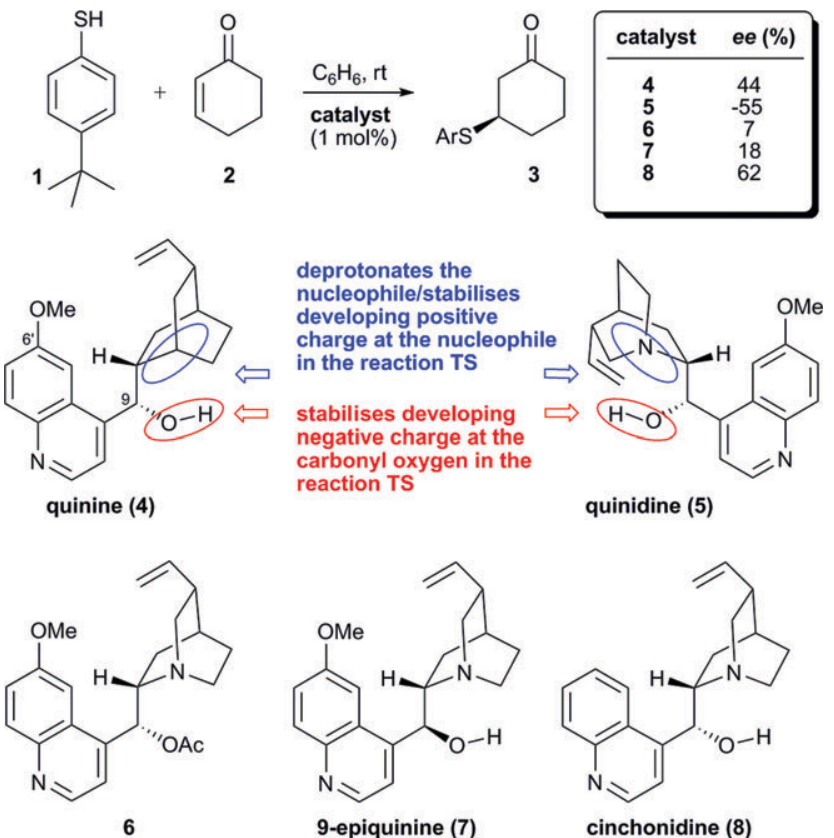

Scheme 1 Bifunctional alkaloid-mediated catalysis by Wynberg.

which were known to be capable of donating two hydrogen bonds to a range of organic and inorganic Lewis-bases, ${ }^{11}$ therefore it was reasonable to expect that they would be capable of accelerating reactions by forming LUMO-lowering hydrogen bonds to Lewis-basic functionality on an electrophilic reaction component (or, by stabilising developing negative charge at heteroatoms in the transition states of addition reactions). ${ }^{12}$ In 1998, Sigman and Jacobsen disclosed that chiral (thio)urea derivatives could efficiently transfer stereochemical information - the chiral $\alpha$-amino acid-derived catalyst 10 proved capable of promoting highly enantioselective Strecker reactions of $\mathrm{N}$-allyl aldimines. ${ }^{13}$ Schreiner and coworkers were the first to show how profoundly catalyst activity can be tuned by simply varying the $N$-aryl substituent and introduced the now almost uniform $N$-trifluoromethylphenyl substituent (i.e., catalyst 11, Fig. 1) which in all likelihood increases both the solubility and $\mathrm{N}-\mathrm{H}$ acidity (and hence hydrogen-bond donating ability) of these materials. It has also been postulated that this substituent can increase catalyst rigidity by facilitating an intramolecular hydrogen-

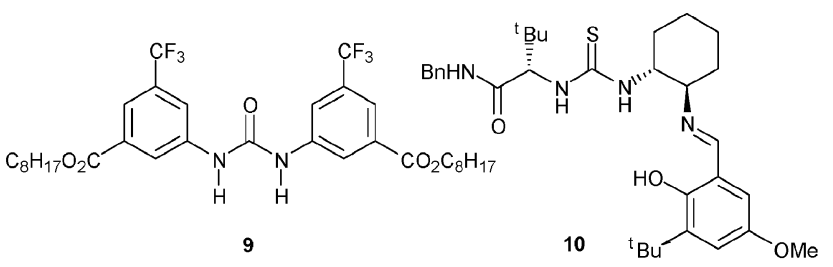<smiles>FC(F)(F)c1cc(NC(=S)Nc2cc(C(F)(F)F)cc(C(F)(F)F)c2)cc(C(F)(F)F)c1</smiles>

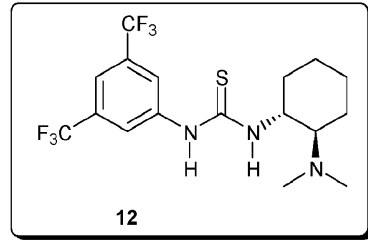

Fig. 1 The first examples of (thio)urea catalysts. bonding interaction between the thiourea sulfur atom and a polarised $o$-aryl proton. ${ }^{14}$

In 2003, Takemoto and co-workers developed these concepts further with the introduction of the 1,2-trans-cyclohexyldiamine-derived thiourea catalyst 12. This molecule represents a logical extension of Curran's, Jacobsen's and Schreiner's ideas, with the added advantage of including bifunctionality as a design element. The authors convincing demonstrated that thiourea $\mathbf{1 2}$ operates via a bifunctional mechanism in the catalysis of highly enantioselective Michael additions of dimethylmalonate to nitroalkenes at room temperature $^{15}$ - the Lewis acidic thiourea moiety is proposed by the authors to activate the nitroalkene electrophile by hydrogen bonding while the basic amine deprotonates the pronucleophile. ${ }^{16,17}$ Catalyst analogues devoid of either the thiourea or the amine component gave poor results under the same conditions.

In view of the precedent set by Takemoto's bifunctional catalyst 12, the development of thiourea-substituted cinchona alkaloid catalysts (general structure in Fig. 2) was the next logical step. Cinchona alkaloids are inexpensive starting materials readily available in both pseudoenantiomeric forms. They possess relatively rigid (but not completely locked) structures in which Brønsted basic and hydrogen bond-accepting functionality are located at stereogenic centres in close proximity to one another. ${ }^{18}$ Furthermore, the C-9 stereocentre is a secondary alcohol, which can readily be transformed into a (thio)urea derivative via the corresponding primary amine. The absolute configuration of the alcohol can be readily inverted if required, which allows the influence of the relative stereochemistry at the Lewis basic and Lewis acidic groups on both activity and selectivity to be determined.

Thus four research groups began working independently on the design of readily accessible and tunable (from steric-, stereochemical- and electronic standpoints, Fig. 2) bifunctional catalyst templates based on cinchona alkaloids and reported their results within a half a year of one another. The first report came from Chen and co-workers ${ }^{19}$ who found that the thiourea substituted cinchonidine and cinchoninederived catalysts 13 and 14, respectively were highly active promoters of the Michael addition of thiophenol to $\alpha, \beta$-unsaturated imide $\mathbf{1 5}$, however catalysis proceeded with low enantioselectivity (Scheme 2).

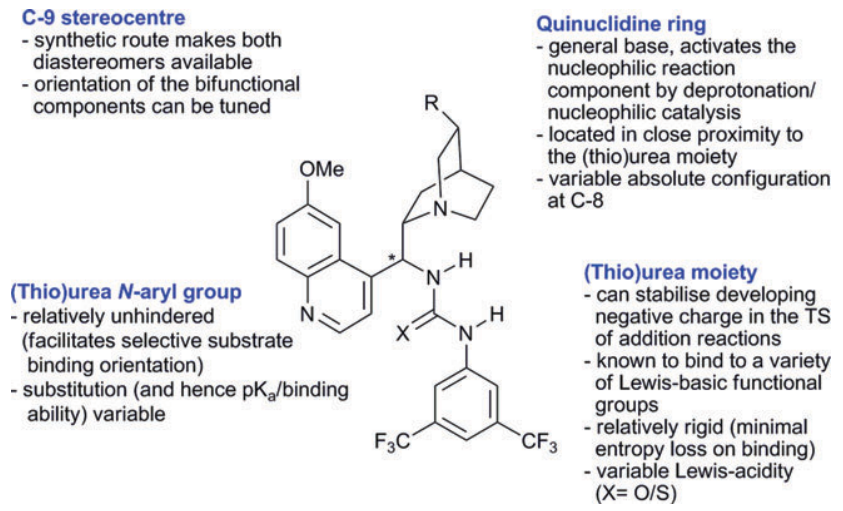

Fig. 2 (Thio)urea-modified cinchona alkaloid catalysts: design elements. 


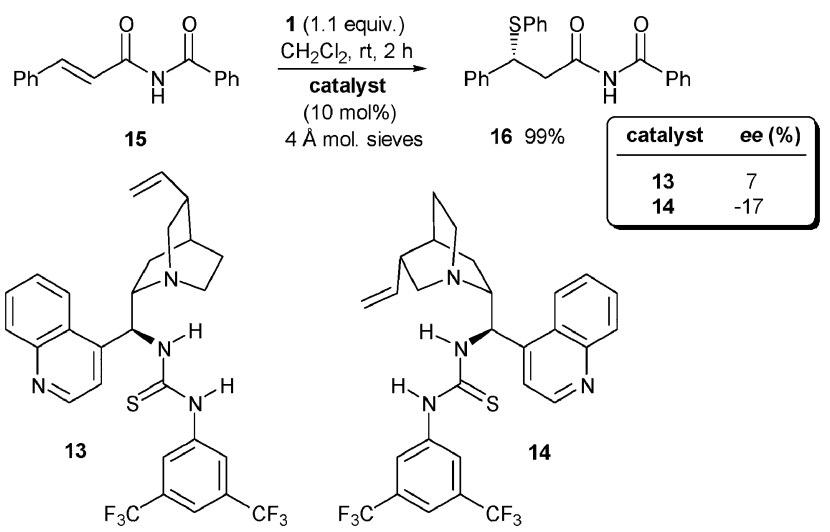

Scheme 2 The first report of thiourea-substituted cinchona alkaloid mediated catalysis by Chen and co-workers

Soós and co-workers ${ }^{20}$ developed thiourea-substituted quinine/quinidine-derived cinchona alkaloid catalysts 17-20 (Scheme 3) for the enantioselective addition of nitromethane to chalcones. These materials were devised to probe both the potential for bifunctional catalysis and the optimal relative stereochemistry at C-8 and C-9. Somewhat surprisingly (given how useful the "privileged"21 core cinchona alkaloid structure and stereochemistry have proven as a basis for ligand/catalyst design in the past) the thiourea derivative of 'natural' stereochemistry at C-9 (i.e. 17) exhibited no catalytic activity (quinine itself was also inactive) while its C-9 epimers (18 and 19) proved both active and highly selective under identical conditions. The relationship between catalyst activity and the relative orientation of the thiourea and quinculidine moieties strongly indicated that these systems operate via a bifunctional mechanism. Long reaction times were required to achieve satisfactory yields at ambient temperature, however heating the reactions to $50-75{ }^{\circ} \mathrm{C}$ resulted in more acceptable rates with low catalyst loadings (as low as $1-2 \mathrm{~mol} \%$ ) without an impractical erosion of either product yield or enantioselectivity.

A short time later our group ${ }^{22}$ and then Dixon and coworkers ${ }^{23}$ independently reported the design of similar catalyst systems for use in the asymmetric addition reactions of
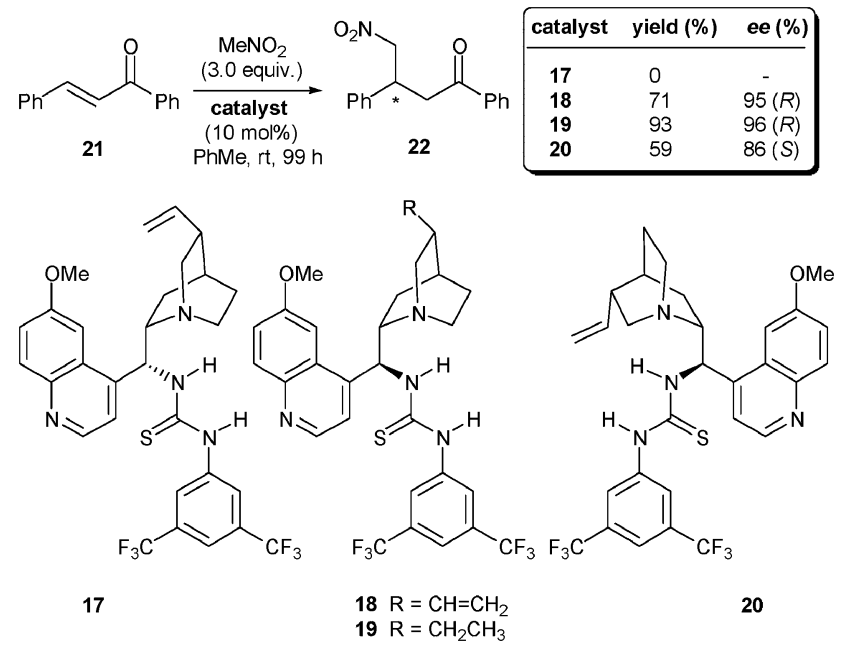

Scheme 3 Catalysis of the addition of nitromethane to chalcone.

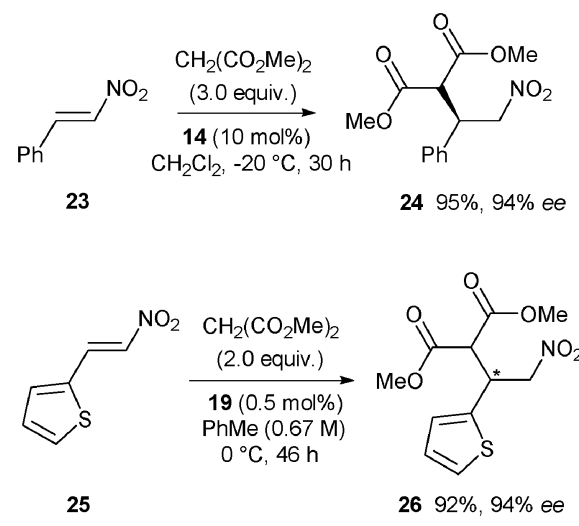

Scheme 4 Catalysis of the addition of dimethylmalonate to nitroolefins.

dimethyl malonate to nitroalkenes. Dixon found that the cinchonine-derived catalyst $\mathbf{1 4}$ could efficiently promote the addition of malonate ester derivatives to $(E)$ - $\beta$-nitrostyrene (23) at $-20{ }^{\circ} \mathrm{C}$ to furnish adduct $\mathbf{2 4}$ in excellent yield and enantioselectivity (Scheme 4). In a similar study we prepared a suite of cinchona alkaloid derivatives for use in the same reaction and demonstrated, by analogy with Soós' results, that while neither epimerisation of the dihydro analogue of the parent alkaloid at C-9 nor substitution of the C-9 hydroxy group with an $N$-aryl(thio)urea moiety without epimerisation improved catalyst activity, a catalyst incorporating both modifications proved both highly efficient and selective (i.e. catalyst 19). The high activity of $\mathbf{1 9}$ is underlined by the synthesis of the thienyl nitroalkane $\mathbf{2 6}$ in $92 \%$ yield and $94 \%$ ee using as little as $0.5 \mathrm{~mol} \%$ of catalyst under mild reaction conditions.

\section{Catalyst application: general}

Due largely to their ready accessibility, the synthetic potential of this class of catalyst has been quickly recognised and exploited by several researchers. It is a testament to the wide utility of these systems that writing almost precisely three years after the submission of the first report concerning their use, sufficient material has appeared to warrant the organisation of the remainder of this review according to reaction class and electrophile type.

\section{Catalyst application: 1,4-addition reactions}

While the field is still very much in its infancy, already it can be stated that (thio)urea-modified cinchona alkaloids have proven particularly adept at the catalysis of asymmetric Michael reactions (vide supra). The following section details developments in this area categorised according to the class of Michael acceptor substrate involved.

\section{Nitroalkenes}

Nitroalkenes have proven an attractive substrate class to date. Nitro-groups possess two co-planar Lewis-basic oxygen atoms capable of accepting two hydrogen bonds ${ }^{11 b}$ from (thio)urea derivatives and the enantioenriched nitroalkane adducts derived from the asymmetric addition of pronucleophiles to 
<smiles></smiles><smiles>O=C([AlH2])C(Cl)C[13C](=O)[O-]</smiles>

$27 \mathrm{Cy}=$ cyclohexyl

28 (1.5 equiv.)

$29 \mathrm{Ar}=4-\mathrm{Cl}-\mathrm{C}_{6} \mathrm{H}_{4}$ $67 \%, 74 \%$ ee

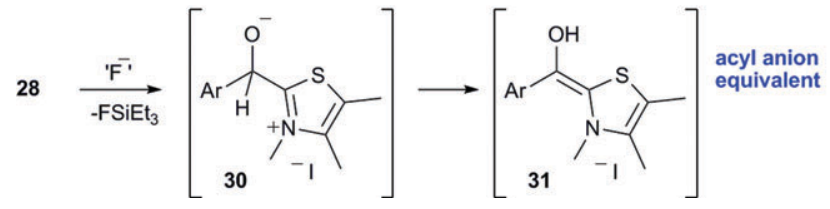

Scheme 5 An umpolung Michael reaction promoted by 18 .

nitroalkenes are highly pliable synthetically. ${ }^{24,25}$ Scheidt and co-workers ${ }^{26}$ discovered a method for synthesising an adduct formally derived from a Stetter-type addition of an acyl anion equivalent to a nitroolefin. Treatment of a mixture of nitroalkene $\mathbf{2 7}$ and thiazolium ion $\mathbf{2 8}$ in the presence of a fluoride ion source and stoichiometric amounts of $\mathbf{1 8}$ resulted in the formation of $\beta$-nitroketone 29 with good levels of enantioselectivity (Scheme 5). It was posited that $\mathbf{2 8}$ serves as a precursor to an acyl anion equivalent - on desilylation it forms alkoxide $\mathbf{3 0}$ which could form Breslow intermediate $\mathbf{3 1}$ (the nucleophilic reaction component) via a proton transfer process. While the reaction is not catalytic in thiourea and only a single enantioselective example was reported, this first report of a direct nucleophilic addition of a carbonyl unit to a nitroalkene is nonetheless of some significance and holds considerable synthetic promise.

In a related study to that outlined in Scheme 4, we found that halomalonates could also be added to nitroalkenes in the presence of 19, which allowed the first asymmetric Michael addition-cyclopropanation reaction sequence involving these substrates. ${ }^{27} 2 \mathrm{Mol} \%$ of 19 catalysed the addition of chlorodimethylmalonate to nitroalkene 32. The Michael adduct could be filtered off and immediately dissolved in HMPA, whereupon addition of the strong amine base 1,8-diazabicyclo[5.4.0]undec-7-ene (DBU) resulted in cyclisation to afford the densely functionalised nitrocyclopropane $\mathbf{3 3}$ as a single diastereomer with moderate enantioselectivity (Scheme 6).

The organocatalytic asymmetric addition of secondary phosphines to nitroalkenes has been achieved by Melchiorre and co-workers. ${ }^{28}$ Catalyst screening studies identified $\mathbf{1 9}$ as the optimum promoter of the addition of diphenylphosphine (35) to nitroolefins at low temperature. Relatively high catalyst loadings are required to furnish $\mathbf{3 6}$ in good yield and moderate ee (after protection with in situ formed borane, Scheme 7), however the products can be enantioenriched almost to optical
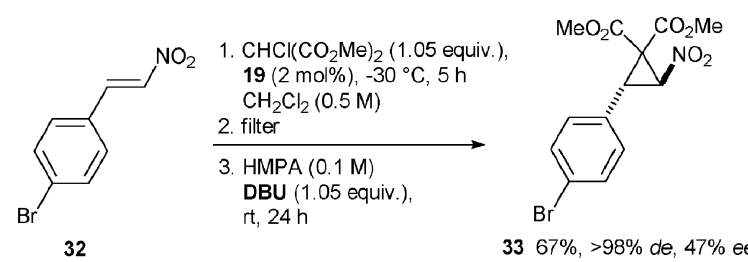

Scheme 6 An asymmetric Michael addition-cyclopropanation reaction sequence.

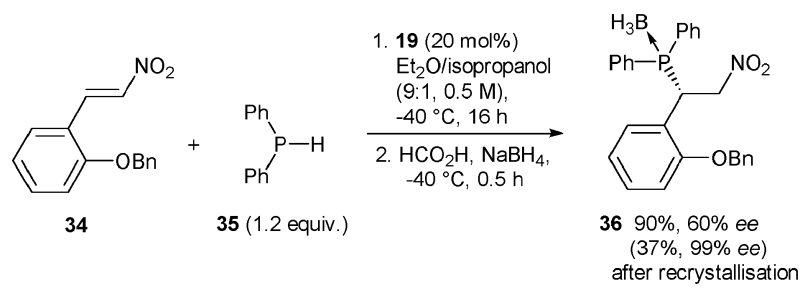

Scheme 7 Asymmetric hydrophosphination.

purity by recrystallisation and are of obvious general interest as ligand candidates in metal-based catalyst systems and are difficult to prepare by other methods.

Dixon and co-workers ${ }^{29}$ added acidic 5-aryl-1,3-dioxolanone heterocycles derived from mandelic acid derivatives and hexafluoroacetone to nitrostyrenes in the presence of the cinchonine-derived catalyst $\mathbf{1 4}$. The products of these reactions are highly versatile and can be easily converted to a range of $\alpha$-hydroxy acid derivatives. While the diastereoselectivity observed in these processes was close to perfect in most cases, both reaction yield and product enantiomeric excess ranged from $c a$. 60 to $c a .90 \%$. Nitroolefin substrates incorporating ortho-substitution furnished the products with the higher enantiopurity than less hindered analogues, albeit at the expense of reaction rate (Scheme 8).

The use of naphthols as the nucleophilic reaction component in Friedel-Crafts type reactions has been reported by Chen and co-workers. ${ }^{30}$ This example is of interest; unlike the cases detailed so far, here the pronucleophile is activated by the amine unit of catalyst 14, but not at the atom forming a bond to the electrophile. Using the nitroalkene as the limiting reagent good yields and enantioselectivity between 85 and $95 \%$ ee could be obtained at low temperatures across a range of aryl- and alkyl-substituted nitroalkene derivatives (Scheme 9). An example of the use of 1-naphthol as the nucleophile was reported to furnish the adduct with lower yield and selectivity $(67 \%, 80 \%$ ee). After extended reaction times the authors noticed that the catalyst could promote the dimerisation of the Friedel-Crafts adduct to give $\mathbf{4 3}$ (Scheme 9).

Inspired by the mode of action of polyketide synthases, which catalyse decarboxylative acylation reactions of CoAbound malonic acid half-thioesters in the biosynthesis of fatty acids and polyketides (A, Scheme 10), Wennemers and Lubkoll $^{31}$ proposed that a (thio)urea-substituted cinchona alkaloid catalyst could play the oxyanion-stabilising role performed by Asn and His conjugate acid residues in the enzymatic system, while the catalyst's amine unit could deprotonate the substrate, thereby forming an ammonium ion which could, in principle, activate a nitroolefin electrophile (B,
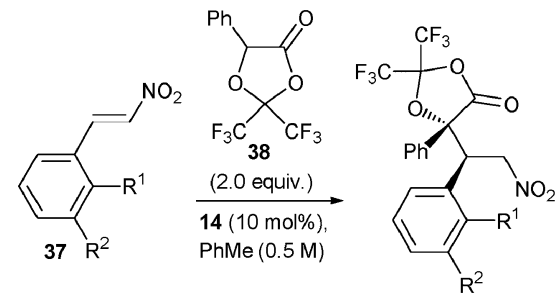

$39 \mathrm{R}^{1}=\mathrm{Br}, \mathrm{R}^{2}=\mathrm{H}, 336 \mathrm{~h}$, $58 \%,>98 \%$ de, $89 \%$ ee $40 \mathrm{R}^{1}=\mathrm{H}, \mathrm{R}^{2}=\mathrm{Br}, 30 \mathrm{~h}$, $71 \%,>98 \%$ de, $68 \%$ ee

Scheme 8 Asymmetric addition of dioxolanones to nitroalkenes. 


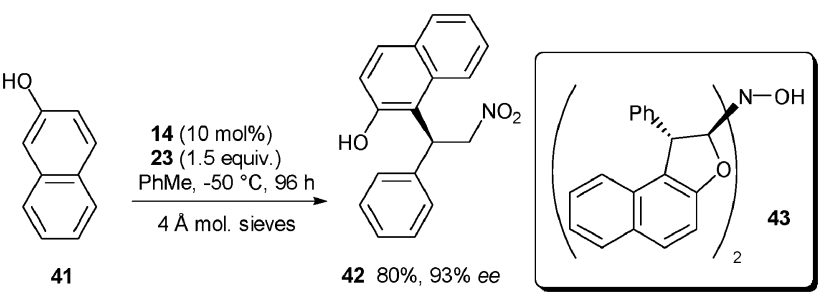

Scheme 9 Catalysis of an asymmetric Friedel-Crafts-type reaction.

Scheme 10). Catalyst screening identified urea 44 as being superior to the corresponding thiourea analogue, ${ }^{32}$ this catalyst could promote an asymmetric decarboxylation/Michael addition between thioester 45 and 23 to give adduct 46 in good yield and enantioselectivity. The choice of solvent is important in these reactions - the processes are more efficient in THF but more selective in ethyl vinyl ether.

Jørgensen and co-workers ${ }^{33}$ demonstrated the enantioselective addition of oximes to nitroolefins catalysed by either $\mathbf{1 8}$ or 20 (Scheme 11). For instance the oxy-Michael addition of ethyl glyoxalate oxime 47 to nitroalkene 27 in the presence of $18(5 \mathrm{~mol} \%)$ allowed the isolation of adduct 48 in good yield and $90 \%$ ee. The method is general for nitroolefin substrates with aliphatic substitutents, however nitrostyrenes are not compatible due to a competitive retroMichael process.

\section{$\alpha, \beta$-Unsaturated ketones}

Ketones possess a single Lewis-basic heteroatom which has been shown to be capable of accepting two hydrogen bonds from urea derivatives ${ }^{11,34}$ and thus it is perhaps unsurprising that enones have also been shown to be useful substrates
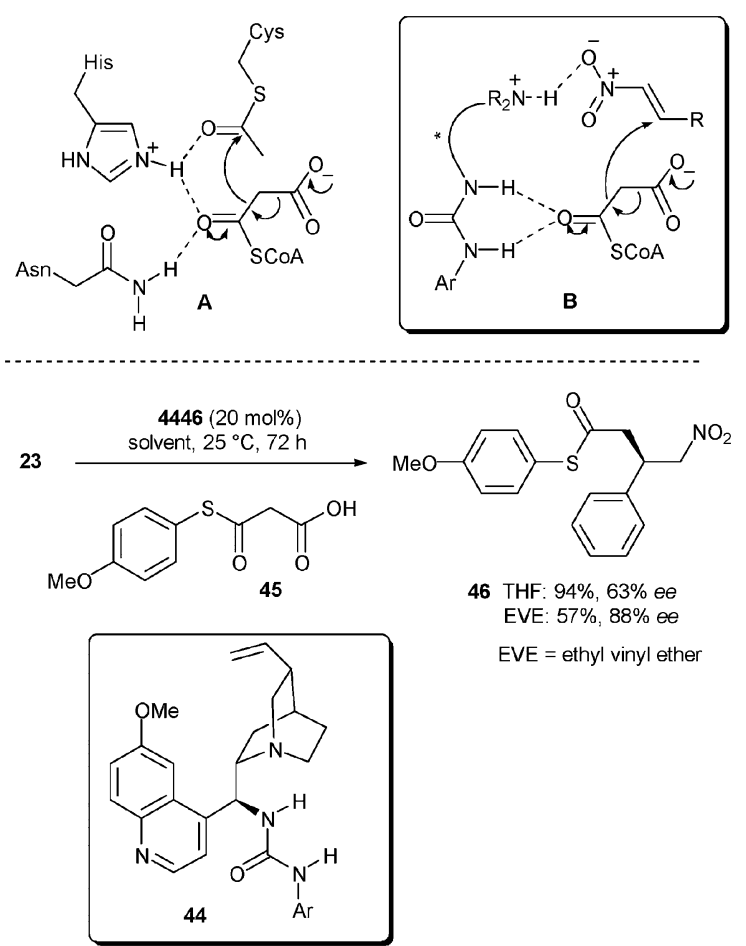

EVE $=$ ethyl vinyl ether

Scheme 10 A biomimetic asymmetric decarboxylative Michael reaction.

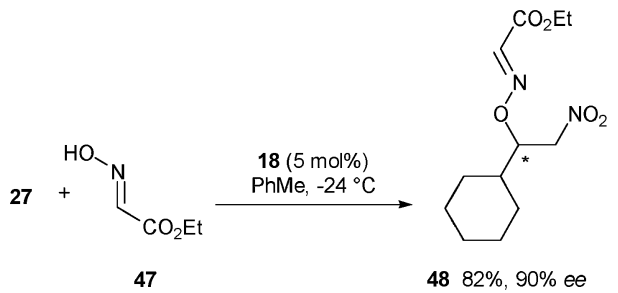

Scheme 11 Oxime-addition to nitroolefins.

for use in conjunction with thiourea modified cinchona alkaloids. After Soos' seminal work in this area, bifunctional thiourea-catalysed additions of thioacetic acid and $\alpha$-substituted cyanoacetates to chalcone and methyl vinyl ketone, respectively were reported by the groups led by Wang ${ }^{35}$ and Chen $^{36}$ (Scheme 12). The latter case is of interest as stereoselectivity comes not from the formation of an $\mathrm{sp}^{3}$-stereogenic centre on the addition of a nucleophile to a internal activated olefin, but rather from the attack of the Michael acceptor at a single enolate face of the conjugate base of the pronucleophile. In both reactions however Takemoto's catalyst 12 offered superior levels of product enantioselectivity and thus the cinchona alkaloid catalysts were not investigated further.

Wang et al. ${ }^{37}$ investigated the asymmetric addition of carbon acids to chalcones catalysed by 19 at $10 \mathrm{~mol} \%$ levels. These reactions were of exceptionally broad scope - the Michael reaction between a range of acidic pronucleophiles of general type $\mathbf{5 4}$ and $\mathbf{2 1}$ to give adducts $\mathbf{5 5} \mathbf{a}-\mathbf{h}$ could be carried out with excellent efficiency and enantioselectivity at ambient temperature (Scheme 13). It is noteworthy that in these reactions 19 was found to be a superior catalyst to both 18 and 12. Use of a $\beta$-ketoester substrate resulted in the formation of a product with a quaternary stereocentre with high enantio- but poor diastereoselectivity. Further studies determined that the methodology was also robust with respect to the chalcone reaction component: the addition of diethyl malonate to chalcones of variable steric and electronic characteristics occurs with uniformly high product yields and excellent ee. Chen and co-workers later studied the addition of $\alpha$-cyanoacetate to chalcones. ${ }^{38}$ Again catalyst 19 proved optimal and the reactions proceeded with high enantioselectivity but low diastereoselectivity (ca. $2: 1$ syn : anti in most cases).

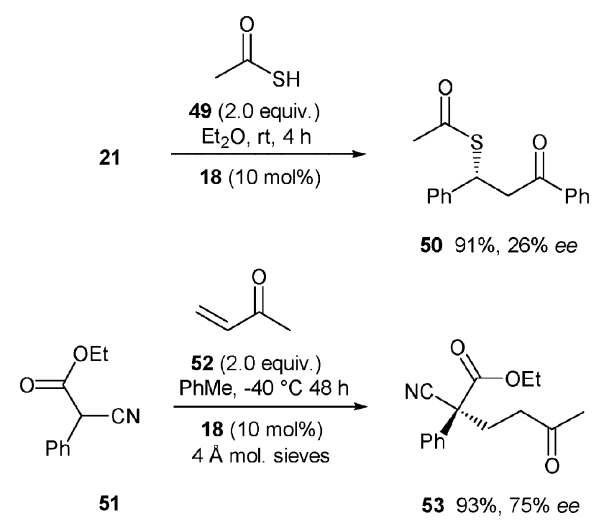

Scheme 12 Addition of thioacetic acid and cyanoacetates to enones. 


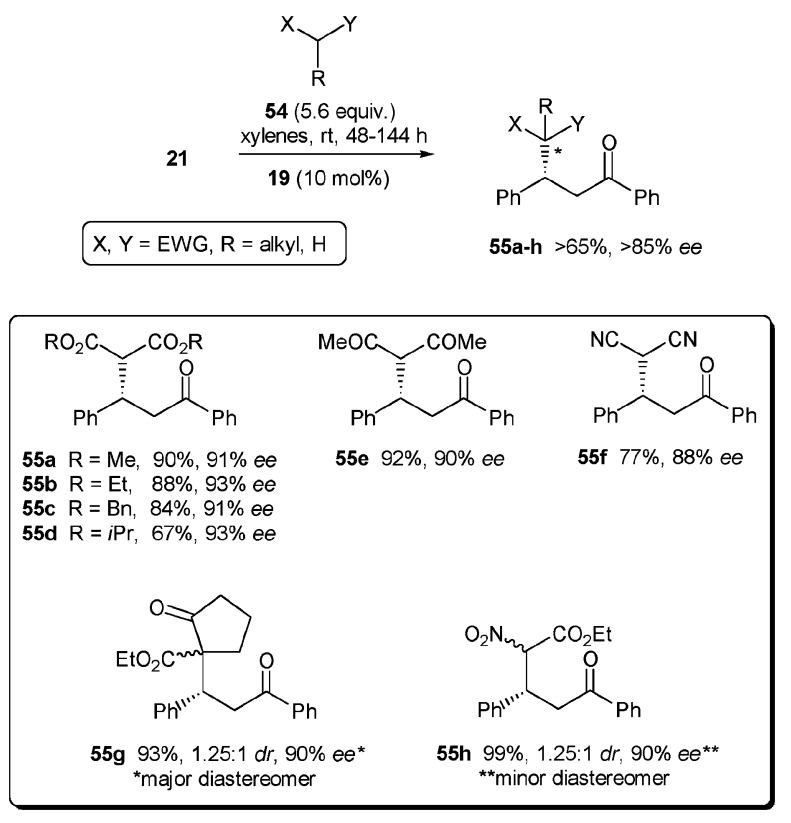

Scheme 13 Addition of a range of acidic pronucleophiles to 21.

Scheidt et al..$^{39}$ have developed a thiourea-catalysed enantioand diastereoselective 6-endo-trig cyclisation reaction of $o$-acyl phenol $\mathbf{5 6}$ to give $\mathbf{5 7}$ with excellent levels of stereocontrol (Scheme 14) using catalyst 18 at $20 \mathrm{~mol} \%$ loading. ${ }^{40} \mathrm{~A}$ subsequent acid catalysed tert-butyl ester deprotection/decarboxylation sequence could also be carried out in one pot to give derivatives of the medicinally relevant flavanone family if desired. The authors extended this concept further to the one pot synthesis of a chromanone natural product - treatment of a solution of $\beta$-ketoester $\mathbf{5 8}$ and aldehyde $\mathbf{5 9}$ under Knoevenagel conditions in the presence of $\mathbf{1 8}$ led to the condensation of the two carbonyl compounds to form the Michael acceptor substrate capable of being cyclised to form an analogue of $\mathbf{5 7}$ which could be deprotected and decarboxylated in the presence of acid at $80{ }^{\circ} \mathrm{C}$ to yield flindersiachromanone (60) in good yield and ee. It was suggested that the catalyst operates via both hydrogen bonding between the thiourea component and the $\beta$-ketoester moiety and deprotonation of the phenol nucleophile by the quinuclidine ring. This proposal was supported by the observation that the monofunctional catalyst $N, N$-bis-trifluoromethylphenyl thiourea failed to promote the<smiles>CCOC(=O)C(=Cc1ccccc1)C(=O)c1ccccc1O</smiles>

56

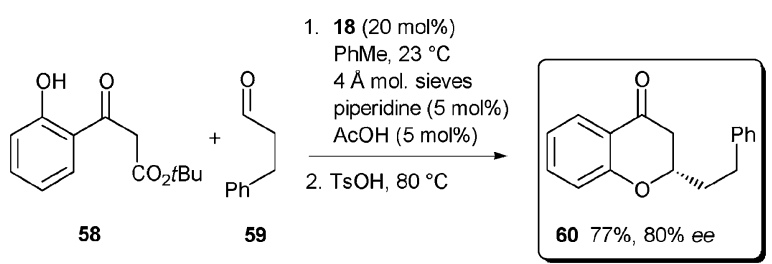

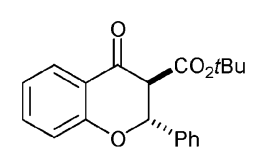

$5797 \%, \geq 20: 1 d r, 80 \%$ ee
Scheme 14 Asymmetric synthesis of flavanones and chromanones.

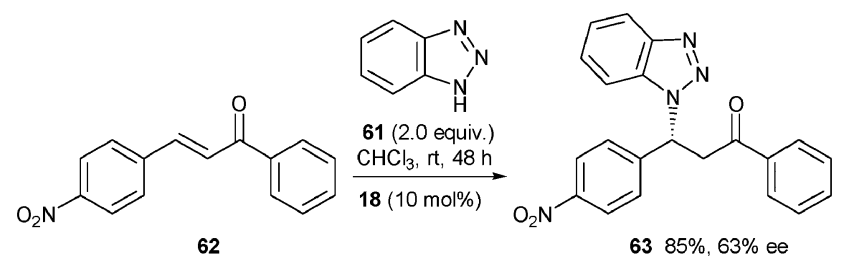

Scheme 15 Asymmetric addition of benzotriazole to chalcones.

reaction, while neither quinine nor a combination of quinine and the aforementioned thiourea catalysed the reaction with high ee.

The addition of a heterocyclic pronucleophile to chalcones has also been reported. ${ }^{41}$ These reactions are not as enantioselective as those involving carbon-based nucleophiles detailed in Scheme 12. Under optimum conditions $1 H$-benzotriazole (61) could be added to chalcone $\mathbf{6 2}$ in the presence of $\mathbf{1 8}$ to furnish the heterocyclic adduct $\mathbf{6 3}$ in good yield and moderate enantiomeric excess (Scheme 15).

\section{$\alpha, \beta$-Unsaturated amides ${ }^{42}$}

In a extension of the methodology from Chen's group ${ }^{19}$ which marked the introduction of thiourea-modified cinchona alkaloid catalysts, Wang and co-workers ${ }^{43}$ have discovered a highly efficient organocatalysed stereoselective tandem Michael-aldol reaction sequence (Scheme 16). Exposure of oxazolidinone 64 to a 1.5 -fold excess of thiophenol $\mathbf{6 5}$ in the presence of just $1 \mathrm{~mol} \%$ of catalyst $\mathbf{1 8}$ in 1,2-dichloroethane gives the cyclised product $\mathbf{6 6}$ with excellent yield and outstanding levels of control over the formation of three new contiguous stereocentres. Subsequent studies revealed that the steric and electronic characteristics of both the oxazolidinone aryl substituent and the thiophenol pronucleophile exerted minimal influence over either reactivity or selectivity (reported yields $>75 \%$, selectivity $>90 \%$ ee, $>20: 1 \mathrm{dr}$ in all cases).

\section{$\alpha, \beta$-Unsaturated nitriles}

Deng's group have been interested in the design of catalytic reactions which generate products with two non-contiguous stereocentres. While reactions which generate contiguous stereocentres with good stereocontrol are not uncommon (e.g. vide supra), the analogous stereoselective processes where the chiral centres are not adjacent are comparatively rare. Previously they had reported that the 6 -demethylated cinchona alkaloid catalyst 67 promotes the Michael addition between $\alpha$-chloroacrylonitrile (68) and the $\alpha$-cyanothioester 69 (for example) to give the adduct $\mathbf{7 0}$ with good diastereo- and enantioselectivity (Scheme 17). ${ }^{8 g}$ Later the same group explored the same chemistry with the thiourea catalyst $\mathbf{1 8}$ and its

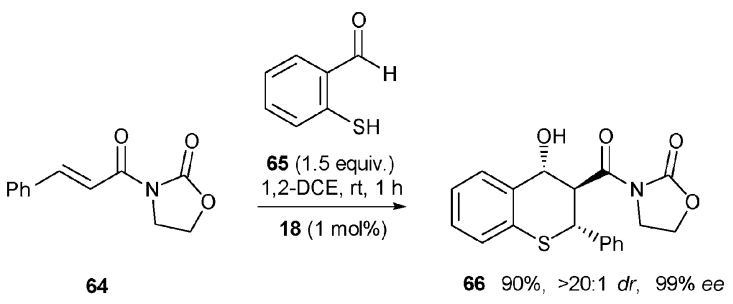

Scheme 16 A highly stereoselective tandem Michael-aldol process. 


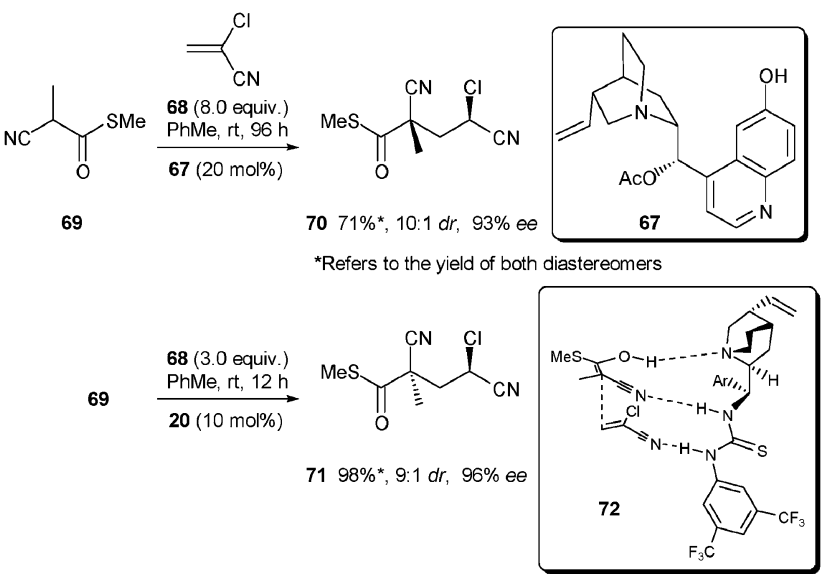

Scheme 17 Formation and control over non-adjacent stereocentres.

quinidine-derived analogue $\mathbf{2 0}$ and found that not only do these materials promote smooth reactions at lower loadings with approximately the same levels of stereocontrol, the adduct formed is the complementary diastereomer (i.e. 71) to that formed using $67 .{ }^{44}$ Thus by using both the quinine and quinidine-derived analogues of both catalyst systems any one of the four diastereomers of $\mathbf{7 0}$ (and a wide range of related analogues derived from variants of 69) can be synthesised with in high enantiopurity under mild conditions. A stereochemical model (model using catalyst $\mathbf{1 8}$ shown) was proposed involving the activation of the pronucleophilie by the thiourea unit and the quinuclidine moiety while the Michael acceptor also accepts a hydrogen bond from the thiourea catalyst component - allowing both the Michael addition and subsequent proton transfer reaction to occur in a controlled chiral environment.

\section{Vinyl sulfones}

The potential of vinyl sulfones to serve as synthetically versatile (hydrogen-bond accepting) substrates in catalytic asymmetric Michael addition reactions has begun to be realised recently. ${ }^{45,46}$ Chen and co-workers ${ }^{47}$ screened a range of bifunctional thiourea-based organocatalysts as promoters of the addition of $\alpha$-substituted cyanoacetates to vinyl sulfone (73). While both Takemoto's thiourea and modified cinchona alkaloids bring about efficient catalysis at room temperature, product enantiomeric excess was moderate. Somewhat surprisingly, use of the more flexible catalyst $\mathbf{7 5}$ resulted in more selective addition and under optimum conditions $\mathbf{7 4}$ could be prepared in good yield and 94\% ee (Scheme 18). Further investigation of the substrate scope determined that the a variety of different $\alpha$-aryl cyanoacetates are compatible with the methodology and that $\alpha$-alkyl cyanoacetates can be added to 1,1-bis-vinylsulfones, albeit generally with lower enantioselectivity.

\section{Catalyst application: 1,2-addition reactions}

\section{Imines}

Asymmetric addition reactions to imines and their derivatives were the first transformations to succumb to catalysis by chiral
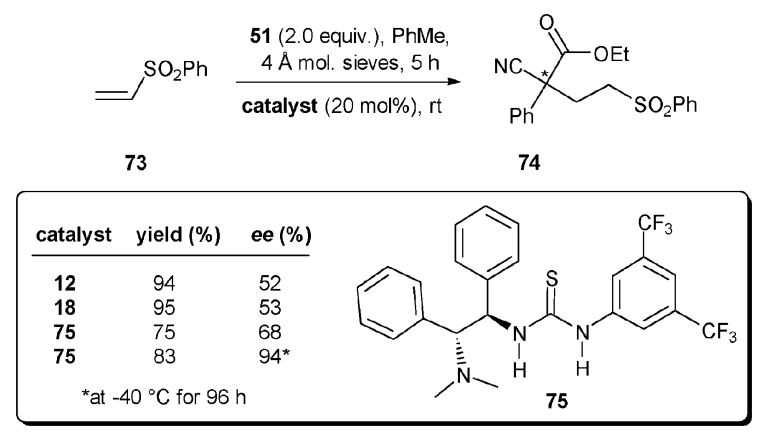

Scheme 18 Addition of $\alpha$-aryl cyanoacetates to vinyl sulfone.

(thio)urea derivatives. ${ }^{48}$ This precedent, together with the general importance of the development of new routes to enantioenriched amines prompted the rapid application of thiourea-substituted cinchona alkaloids to the catalysis of addition reactions to imines.

The first such report detailed the asymmetric addition of nitromethane to a variety of $\mathrm{N}$-protected aromatic aldimines. Ricci et $a l^{49}$ demonstrated that of eight quinine-derived compounds of variable substitution and absolute configuration at C-9 tested (including the parent alkaloid itself) $\mathbf{1 8}$ proved the most active and enantioselective as a catalyst for the aza-Henry reaction ${ }^{50}$ between nitromethane and the $N$-Boc imine derived from benzaldehyde. Other carbamate protecting groups gave similar results, however, use of phosphinoyl-, tosyl, aryl and simple amide protecting groups resulted in diminished product enantioselectivity. Subsequent optimisation of the reaction conditions resulted in a highly enantioselective addition of nitromethane to optimal substrate $\mathbf{7 6}$ catalysed by $20 \mathrm{~mol} \%$ of $\mathbf{1 8}$ to give the $\beta$-nitro amine product 77 with excellent enantiopurity (Scheme 19).

In a similar study Schaus and co-workers ${ }^{51}$ utilised 19 to promote the same reaction class involving methylcarbamate derivatives and a relatively large excess of nitromethane in dichloromethane solvent at $-10{ }^{\circ} \mathrm{C}$. Under these conditions the aromatic Mannich adducts $\mathbf{8 1 - 8 3}$ could be isolated with $>90 \%$ ee (Scheme 19). When nitroethane was used as the pronucleophile under otherwise identical conditions excellent syn-diastereoselectivity results without a significant erosion of enantioselectivity (Scheme 19). Based on molecular modeling studies the authors proposed a rationale to explain the stereoselectivity observed which hinges on the binding of the pronucleophile conjugate base (and not the electrophile) to both the thiourea moiety and the protonated quinuclidine catalyst component. ${ }^{51,52}$

Dixon and co-workers ${ }^{53}$ extended the scope of this reaction to include dicarbonyl pronucleophiles. Acetyl acetone, malonate esters and $\beta$-ketoesters could all participate in an asymmetric Mannich reaction ${ }^{54}$ with $N$-carbamoyl protected imines with good to excellent product enantiomeric excess (particularly in the case of the latter two pronucleophile classes) in the presence of $\mathbf{1 4}$ at low temperature. For example, the Cbz-protected aldimine 87 underwent a clean Mannich reaction with dimethylmalonate, which allowed the isolation of adduct $\mathbf{8 8}$ in essentially quantitative yield and $97 \%$ ee. The hydrolysis and decarboxylation of representative adducts to reveal orthogonally protected $\beta$-amino acid derivatives without racemisation in a one-pot 
<smiles>O=C(N=Cc1ccc2ccccc2c1)c1ccccc1</smiles>

76<smiles>[R]c1cccc(/C=N/C(=O)OC)c1</smiles>

$$
78 \mathrm{R}=\mathrm{H}
$$$$
79 \mathrm{R}=\mathrm{Me}
$$$$
80 \mathrm{R}=\mathrm{F}
$$
tions.
PhMe, $-40^{\circ} \mathrm{C}, 38 \mathrm{~h}$ $\mathrm{MeNO}_{2}$ (5.0 equiv.) $18(20 \mathrm{~mol} \%)$

$\mathrm{CH}_{2} \mathrm{Cl}_{2},-10^{\circ} \mathrm{C}, 48 \mathrm{~h}$ $\mathrm{MeNO}_{2}$ (10.0 equiv.)

$19(10 \mathrm{~mol} \%)$<smiles>CC(C)(C)OC(=O)N[C@H](C[N+](=O)[O-])c1ccc2ccccc2c1</smiles>

$7782 \%, 94 \%$ ee<smiles>[R]c1cccc(C(C[N+](=O)[O-])NC(=O)OC)c1</smiles>

$81 \mathrm{R}=\mathrm{H}, 91 \%, 93 \%$ ee $82 \mathrm{R}=\mathrm{Me}, 98 \%, 91 \%$ ee $83 \mathrm{R}=\mathrm{F}, 98 \%, 98 \%$ ee

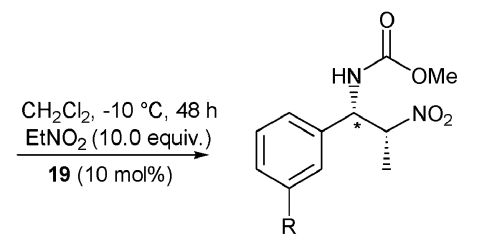

$84 \mathrm{R}=\mathrm{H}, 96 \%, 83 \%$ de, $94 \% \mathrm{ee}^{* *}$ $85 \mathrm{R}=\mathrm{Me}, 98 \%, 90 \%$ de, $97 \%$ ee $86 \mathrm{R}=\mathrm{F}, \mathbf{9 8 \%}, 97 \%$ de, $91 \%$ ee

** reaction run for $24 \mathrm{~h}$
Scheme 19 Modified cinchona alkaloid catalysed aza-Henry reac-

procedure was also demonstrated. $\beta$-Ketoesters such as methylcyclopentanone-2-carboxylate (89) reacted with similar efficiency and good diastereoselectivity but enantioselectivity was inferior to that observed using malonates (Scheme 20). Shortly afterwards first Deng and co-workers ${ }^{55}$ and then Schaus and coworkers ${ }^{51}$ obtained similar findings using quinine and quinidinederived catalyst analogues. Interestingly, Schaus found that smooth and selective ( $>90 \%$ ee) addition to the methyl carbamate 78 in $\mathrm{CH}_{2} \mathrm{Cl}_{2}$ catalysed by $\mathbf{1 8}$ at higher reaction temperatures of $-35{ }^{\circ} \mathrm{C}$.

One of the drawbacks associated with these methodologies is their incompatibility with alkyl-substituted aldimines, which tautomerise to the corresponding enamine derivatives under the reaction conditions. In a separate report, Deng's group ${ }^{56}$ circumvented this problem by generating the substrate in situ from the base-mediated elimination of $\mathrm{HSO}_{2} \mathrm{Ar}$ from $\alpha$-amido sulfones. Under these conditions both Boc- and Cbz-protected aliphatic aldimines could be generated and trapped by dibenzylmalonate catalysed by either $\mathbf{1 8}$ or $\mathbf{2 0}$ at $0{ }^{\circ} \mathrm{C}$. The Cbzprotecting group is superior to a Boc-carbamate in these reactions as the in situ-synthesised imines from the latter substrate class underwent tautomerisation under the reaction conditions. Of the eight $\alpha$-amido sulfone substrates evaluated 92 proved optimal (Scheme 20).

Chen and co-workers found that $\mathbf{1 8}$ catalyses asymmetric vinylogous Mannich reactions between $\mathbf{9 0}$ and $\alpha, \alpha$-dicyanoolefins.

While the enantiomeric excess of the product from this reaction was appreciable ( $61 \%$ ee), a modified analogue of Takemoto's catalyst was shown to be superior in this reaction and no further experimentation with the cinchona alkaloidbased system was reported. ${ }^{57}$

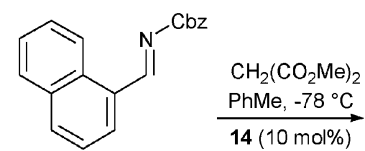<smiles>CC(=O)OCCNC(C(C)=O)c1cccc2ccccc12</smiles>

87<smiles>CC(C)(C)OC(=O)N=Cc1ccccc1</smiles><smiles>CC(=O)C1CCCC1C(C)=O</smiles>

$88>99 \%, 97 \%$ ee<smiles>CO[C@H](c1ccccc1)[C@@H](NC(=O)OCc1ccccc1)[C@]1(O)CCCC1=O</smiles>

$9170 \%, 16: 1,85 \%$ ee

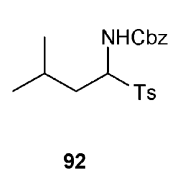

$\mathrm{CH}_{2}\left(\mathrm{CO}_{2} \mathrm{Bn}\right)_{2}(1.5$ equiv.
$\mathrm{CH}_{2} \mathrm{Cl}_{2}, 0^{\circ} \mathrm{C}, 20 \mathrm{~h}$
$\mathrm{CsOH}$ (aq.) (1 equiv.)
$\underset{\mathbf{2 0}(10 \text { mol\%) }}{\mathbf{2 0}}$<smiles>CC(C)CC(NC(=O)OCc1ccccc1)C(=O)OCc1ccccc1</smiles>

$9388 \%, 92 \%$ ee

Scheme 20 Asymmetric modified cinchona-alkaloid catalysed Mannich reactions.

The 3-indolyl methanamine subunit is a constituent of a number of indole-alkaloid natural products. ${ }^{58}$ Recognising a gap in the literature concerning the catalytic asymmetric synthesis of these compounds from indoles and imines via a robust methodology applicable to both aromatic and alkylsubstituted aldimine derivatives, Deng and co-workers ${ }^{59}$ developed the first asymmetric organocatalytic route to this important class of compound using catalysts 18 and 20. A range of substituted indoles could be added to $N$-sulfonyl protected imines with high levels of enantiomeric excess at $50{ }^{\circ} \mathrm{C}$ in concentrated solution. This method offers several advantages over the previous literature benchmark for this reaction ${ }^{60}$ not least of which is the uniformly high enantioselectivity observed regardless of the electronic characteristics of either reaction component. This study also reported the first examples the participation of alkyl imines in this enantioselective Friedel-Crafts-type ${ }^{61}$ process (Scheme 21 ).

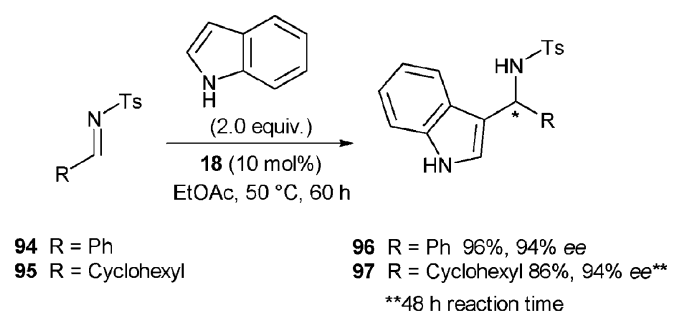

Scheme 21 Asymmetric Friedel-Crafts-type reactions with imine substrates.

\section{Aldehydes}

In 2005 Hiemstra and co-workers ${ }^{62}$ submitted a report demonstrating that C-9 is not the sole position on the cinchona alkaloid backbone where thiourea functionality can be installed with advantage. Substitution of the 6'-OMe group with a thiourea moiety and benzylation of the C-9 hydroxy substituent without disturbing the stereochemical configuration of 
<smiles>O=Cc1ccccc1</smiles>

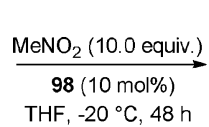

99
$10090 \%, 92 \%$ ee

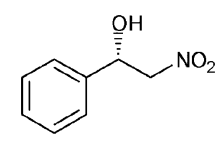
tuted catalyst. asymmetric Henry reaction. ring.

\section{Catalyst application: other reactions}

\section{Diels-Alder reactions}

Scheme 22 Asymmetric Henry reaction catalysed by a C-6' substi-

the natural alkaloid resulted in a powerful catalyst for the

The quinidine-derived catalyst $\mathbf{9 8}$ was capable of promoting the highly enantioselective Henry reaction between nitromethane and aromatic aldehydes (electron rich, electron deficient and hindered variants) in THF at $-20{ }^{\circ} \mathrm{C}$ (Scheme 22). The corresponding quinine-derived catalyst proved just as useful and the authors proposed a mode of action involving activation of the aldehyde by the thiourea unit and deprotonation of the nitromethane acid by the catalyst's quinuclidine

Deng and co-workers ${ }^{63}$ have applied both thiourea-substituted and $C-6^{\prime}$ demethylated cinchona alkaloid derivatives to the catalysis of the Diels-Alder reaction between 2-pyrones and $\alpha, \beta$-unsaturated electrophiles. For example, based on the known ability of $\mathbf{1 8}$ and $\mathbf{2 0}$ to promote asymmetric additions to acrylonitriles, ${ }^{44}$ Deng reasoned that these catalysts could bring about a HOMO-elevating interaction between the quinuclidine nitrogen atom and the hydroxy group of diene 101, and a LUMO-lowering hydrogen-bonding interaction between the thiourea and the nitrile lone pair of dienophile 68. At 5 mol\% loading 18 and 20 could catalyse the formation of $\mathbf{1 0 2 a}, \mathbf{b}$ with good exo-selectivity and excellent enantioselectivity (Scheme 23). Most usefully (as was the case with the study detailed earlier - see Scheme 17), C-6' demethylated cinchona alkaloid derivatives 104 and 105 promote the formation of the corresponding endo-diastereomers 103a,b with high enantiomeric excess and reduced (but synthetically acceptable) diastereoselectivity. Thus all four diastereomeric products can be obtained with high levels of enantiopurity.

\section{Decarboxylative protonation}

Rouden and co-workers ${ }^{64}$ utilised $\mathbf{1 8}$ and $\mathbf{2 0}$ as chiral bases in the decarboxylative protonation of $\alpha$-aminomalonate hemi-
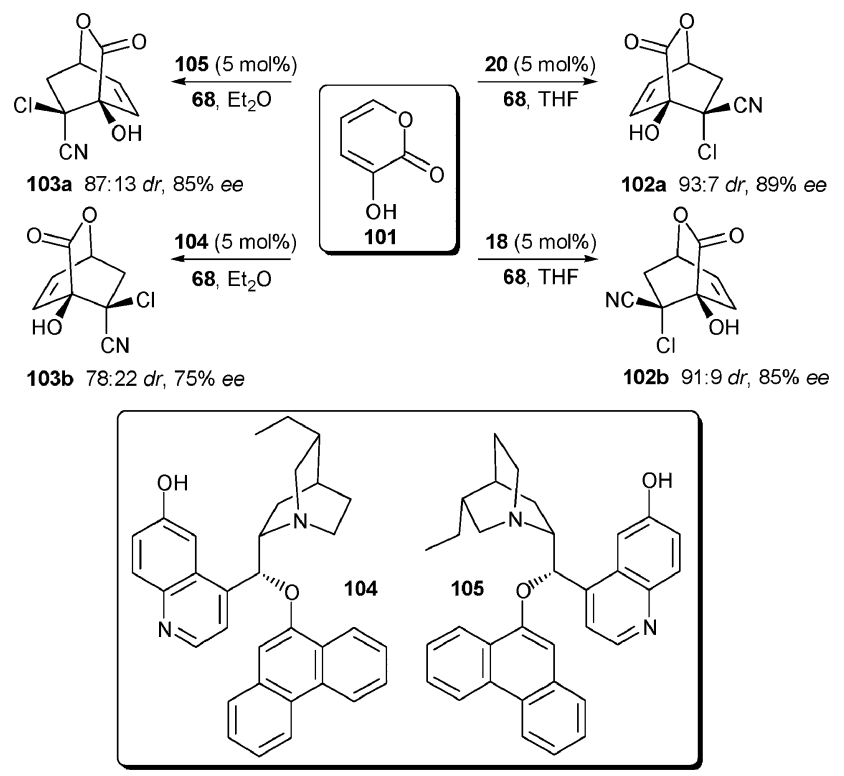

Scheme 23 Asymmetric Diels-Alder reactions

esters. The idea is that treatment of carboxylic acid $\mathbf{1 0 6}$ with the chiral base $\mathbf{1 8}$ would lead to ion pair $\mathbf{1 0 7}$ - the decarboxylation of which leads to ammonium enolate 108. Subsequent proton transfer in a face-selective manner gives the protected $\alpha$-amino acid derivative $\mathbf{1 0 9}$ with regeneration of $\mathbf{1 8}$ (Scheme 24). It was found that this methodology could be successfully applied to a range of protected $\alpha$-aminomalonates. High yields and enantioselectivities (the highest reported for any organic base) were possible at $0{ }^{\circ} \mathrm{C}$ in polar aprotic solvents. While (as the proposed mechanism suggests) 18 can be utilised in catalytic amounts, its activity is not sufficient under these conditions for application at substoichiometric loadings: even at $100 \mathrm{~mol} \%$ levels the reaction requires 7 days to run to completion. A compensating factor is that the catalyst can be readily recycled and reused after reaction.
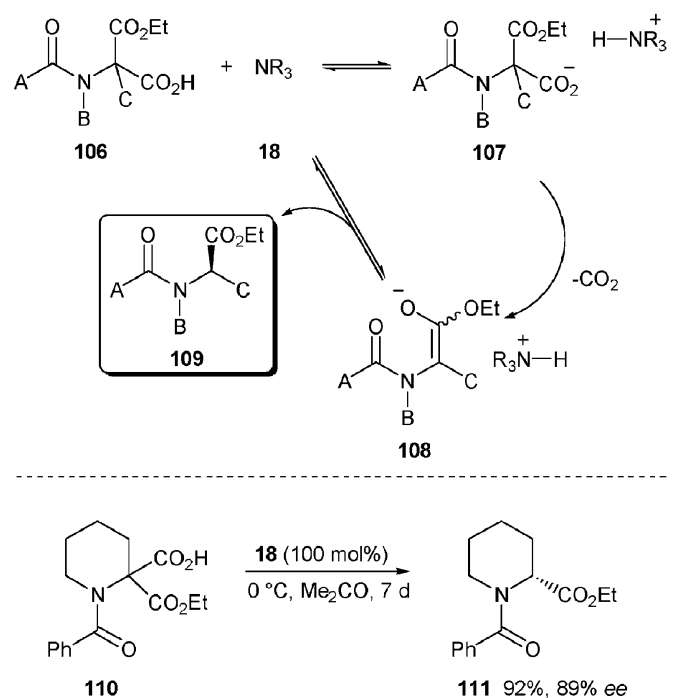

Scheme 24 Enantioselective decarboxylative protonation. 


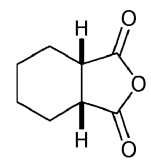

112
$18(1 \mathrm{~mol} \%)$

$\overrightarrow{\mathrm{MeOH}(10.0 \text { equiv.) }}$ $\operatorname{MTBE}(0.015 \mathrm{M}), \mathrm{rt}, 30 \mathrm{~h}$

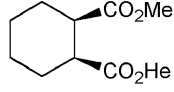

$11398 \%, 93 \%$ ee

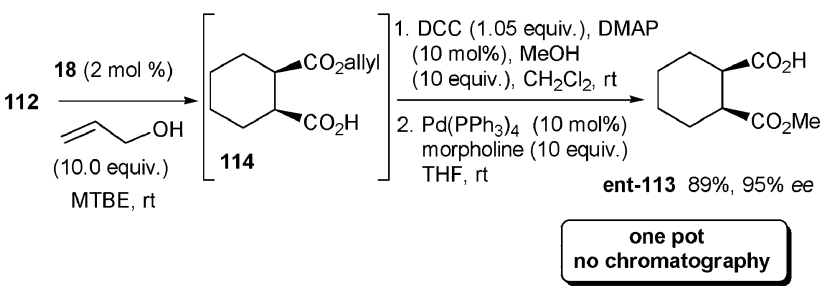

Scheme 25 Desymmetrisation of meso anhydrides.

\section{Desymmetrisation of meso anhydrides}

The catalytic asymmetric desymmetrisation of meso anhydrides via alcoholysis is a powerful methodology for the preparation of synthetically useful hemiesters with the generation of either single or multiple stereocentres with high levels of enantiocontrol. The benchmark catalyst systems for this reaction developed independently by the groups of Bolm ${ }^{65,66}$ and Deng ${ }^{67,68}$ both involve the use of cinchona alkaloid derivatives as general-base catalysts for the addition reaction. While these methodologies are very useful, they are not entirely amenable to use on process scale - excellent yields and enantioselectivities are possible with catalyst loadings of $110 \mathrm{~mol} \%$ or between $5-30 \mathrm{~mol} \%$ and temperatures of $-55^{\circ} \mathrm{C}$ or between -20 and $-40{ }^{\circ} \mathrm{C}$, respectively. We proposed that catalysts capable of also activating the anhydride moiety via hydrogen bonding should offer potential advantages in terms of both rate and selectivity. ${ }^{69}$ Screening studies allowed the identification of conditions under which $1 \mathrm{~mol} \%$ of catalyst 18 promoted the desymmetrisation of $\mathbf{1 1 2}$ (for example) at ambient temperature to give hemiester 113 in excellent yield and enantiomeric excess in $30 \mathrm{~h}$ (Scheme 25). We also found that allyl alcohol could be used as the nucleophile in these reactions - this allows the synthesis of both antipodes of 113 using a single catalyst system via the manipulation of allyl hemiester 114 without chromatography (113 is isolated pure after a simple acid/base wash/extraction sequence).

\section{Conclusions}

It is now almost exactly three years since the submission of the first report detailing the use of thiourea-substituted cinchona alkaloid-based catalysts. In this short time these compounds have proven themselves to be extraordinarily useful catalysts for (inter alia) the 1,4- or 1,2-asymmetric addition of acidic pronucleophiles to a wide range of substrates. The key to their success is their ability to interact with both the 'nucleophilic' and 'electrophilic' reaction components simultaneously and to control their encounter in a well-defined chiral environment. The catalysts are easily synthesised from the readily available alkaloids and have been shown to catalyse enantioselective reactions at temperatures ranging from -78 to $75{ }^{\circ} \mathrm{C}$. Much has already been demonstrated, however the scope and utility of these materials has not yet been fully explored and while it is already certain that their place alongside other modified cinchona alkaloid derivatives in the organocatalysis toolbox is assured, for the time being their contribution to this burgeoning field looks set to continue apace.

\section{Acknowledgements}

Our catalysis work was generously supported by the Irish Research Council for Science, Engineering and Technology and Science Foundation Ireland. The assistance of Aldo Peschiulli in proof-reading the manuscript is gratefully acknowledged.

\section{Notes and references}

1 For selected early examples of asymmetric organocatalysis, see: (a) G. Bredig and K. Fajans, Ber. Dtsch. Chem. Ges., 1908, 41, 752; (b) G. Bredig and P. S. Fiske, Biochem. Z., 1912, 46, 7; (c) R. Wegler, Justus Liebigs Ann. Chem., 1932, 498, 62; (d) V. Prelog and H. Wilhelm, Helv. Chim. Acta, 1954, 37, 1634; (e) H. Pracejus, Justus Liebigs Ann. Chem., 1960, 634, 9; (f) D. Borrmann and R. Wegler, Chem. Ber., 1967, 100, 1575; $(g)$ H. Wynberg and R. Helder, Tetrahedron Lett., 1975, 16, 4057.

2 Selected recent reviews: (a) A. Ting and S. E. Schaus, Eur. J. Org. Chem., 2007, 5797; (b) G. Lelais and D. W. C. MacMillan, in Frontiers in Asymmetric Catalysis, ed. K. Mikami and M. Lautens, Wiley, Hoboken, NJ, 2007; (c) D. Almaşi, D. A. Alonso and C. Nájera, Tetrahedron: Asymmetry, 2007, 18, 299; (d) R. M. de Figueiredo and M. Christmann, Eur. J. Org. Chem., 2007, 2575; (e) S. B. Tsogoeva, Eur. J. Org. Chem., 2007, 1701; (f) M. J. Gaunt, C. C. C. Johansson, A. McNally and N. T. Vo, Drug Discov. Today, 2006, 12, 8; (g) B. List, Chem. Commun., 2006, 819; (h) M. S. Taylor and E. N. Jacobsen, Angew. Chem., Int. Ed., 2006, 45, 1520; (i) S. J. Connon, Chem.-Eur. J., 2006, 12, 5418; (j) T. Akiyama, J. Itoh and K. Fuchibe, Adv. Synth. Catal., 2006, 348, 999; (k) S. J. Connon, Lett. Org. Chem., 2006, 3, 333; (l) Y. Takemoto, Org. Biomol. Chem., 2005, 3, 4299; (m) S. Jayasree and B. List, Org. Biomol. Chem., 2005, 3, 719; (n) P. M. Pihko, Angew. Chem., Int. Ed., 2004, 43, 2062; (o) A. Berkessel and H. Gröger, Asymmetric Organocatalysis, Wiley, Weinheim, 2005; (p) P. I. Dalko and L. Moisan, Angew. Chem., Int. Ed., 2004, 43, 5138; (q) K. N. Houk and B. List, Acc. Chem. Res., 2004, 37(8); (r) P. M. Pihko, Angew. Chem., Int. Ed., 2004, 43, 2062; (s) P. R. Schreiner, Chem. Soc. Rev., 2003, 32, 289.

3 Bifunctionality is by no means the sole preserve of organocatalytic systems, for examples, see: (a) $\mathrm{H}$. Yamamoto and $\mathrm{K}$. Futatsugi, Angew. Chem., Int. Ed., 2005, 44, 1924; (b) M. Kanai, N. Kato, E. Ichikawa and M. Shibasaki, Synlett, 2005, 1491; (c) J.-A. Ma and D. Cahard, Angew. Chem., Int. Ed., 2004, 43, 4566; (d) S. France, A. Weatherwax, A. E. Taggi and T. Lectka, Acc. Chem. Res., 2004, 37, 592; (e) M. Shibasaki and N. Yoshikawa, Chem. Rev., 2002, 102, 2187; (f) H. Gröger, Chem.-Eur. J., 2001, 7, 5247.

4 H. Hiemstra and H. Wynberg, J. Am. Chem. Soc., 1981, 103, 417.

5 For a preliminary report, see: R. Helder, R. Arends, W. Bolt, H. Hiemstra and H. Wynberg, Tetrahedron Lett., 1977, 25, 2181.

6 For a more recent study of this reaction using cinchona alkaloid catalysts, see: P. McDaid, Y. Chen and L. Deng, Angew. Chem., Int. Ed., 2002, 41, 338.

7 Y. Iwabuchi, M. Nakatani, N. Yokoyama and S. Hatakeyama, $J$. Am. Chem. Soc., 1999, 121, 10219.

8 (a) H. Li, Y. Wang, L. Tang and L. Deng, J. Am. Chem. Soc., 2004, 126, 9906; (b) H. Li, Y. Wang, L. Tang, F. Wu, X. Liu, C. Guo, B. M. Foxman and L. Deng, Angew. Chem., Int. Ed., 2005, 44, 105; (c) X. Liu, H. Li and L. Deng, Org. Lett., 2005, 7, 167; (d) H. Li, J. Song, X. Liu and L. Deng, J. Am. Chem. Soc., 2005, 127, 8948; (e) F. Wu, H. Li, R. Hong and L. Deng, Angew. Chem., Int. Ed., 2006, 45, 947; (f) H. Li, B. Wang and L. Deng, 
J. Am. Chem. Soc., 2006, 128, 732; (g) Y. Wang, X. Liu and L. Deng, J. Am. Chem. Soc., 2006, 128, 3928; (h) F. Wu, R. Hong, J. Khan, X. Liu and L. Deng, Angew. Chem., Int. Ed., 2006, 45, 4301.

9 Selected reviews concerning the use of cinchona alkaloid-derivatives as organocatalysts: (a) S.-K. Tian, Y. Chen, J. Hang, L. Tang, P. McDaid and L. Deng, Acc. Chem. Res., 2004, 37, 621; (b) S. France, D. J. Guerin, S. J. Miller and T. Lectka, Chem. Rev., 2003, 103, 2985; (c) K. Kacprzak and J. Gawronski, Synthesis, 2001, 961.

10 (a) D. P. Curran and L. H. Kuo, J. Org. Chem., 1994, 59, 3259; (b) D. P. Curran and L. H. Kuo, Tetrahedron Lett., 1995, 36, 6647.

11 For early examples, see: $(a)$ M. C. Etter and T. W. Panunto, J. Am. Chem. Soc., 1988, 110, 5896; (b) M. C. Etter, Z. UrbañczykLipkowska, M. Zia-Ebrahimi and T. W. Panunto, J. Am. Chem. Soc., 1990, 112, 8415; (c) R. M. Tel and J. B. F. N. Engberts, $J$. Chem. Soc., Perkin Trans. 2, 1976, 483; (d) M. C. Etter, Acc. Chem. Res., 1990, 23, 120; (e) M. C. Etter, J. Phys. Chem., 1991, 95, 4601; (f) T. R. Kelly and M. H. Kim, J. Am. Chem. Soc., 1994, 116, 7072 .

12 For a more detailed discussion of the background to the development of urea and thiourea catalysts see refs. $2 h, 2 i$, $2 l$ and $2 s$.

13 M. S. Sigman and E. N. Jacobsen, J. Am. Chem. Soc., 1998, 120, 4901.

14 (a) P. R. Schreiner and A. Wittkopp, Org. Lett., 2002, 4, 217; (b) P. R. Schreiner and A. Wittkopp, Chem.-Eur. J., 2003, 9, 407.

15 T. Okino, Y. Hoashi and Y. Takemoto, J. Am. Chem. Soc., 2003, $125,12672$.

16 T. Okino, Y. Hoashi, T. Furukawa, X. Xu and Y. Takemoto, J. Am. Chem. Soc., 2005, 127, 119.

17 Pápai and co-workers have recently proposed an alternative mechanistic picture based on computational studies, see: A. Hamza, G. Schubert, T. Soós and I. Pápai, J. Am. Chem. Soc., 2006, 128, 13151.

18 For a recent review of cinchona alkaloid chemistry, see: H. M. R. Hoffmann and J. Frakenpohl, Eur. J. Org. Chem., 2004, 4293.

19 B.-J. Li, L. Jiang, M. Liu, Y.-C. Chen, L.-S. Ding and Y. Wu, Synlett, 2005, 603.

20 B. Vakulya, S. Varga, A. Csámpai and T. Soós, Org. Lett., 2005, 7, 1967.

21 T. P. Yoon and E. N. Jacobsen, Science, 2003, 299, 1691.

22 S. H. McCooey and S. J. Connon, Angew. Chem., Int. Ed., 2005, 44, 6367 .

23 J. Ye, D. J. Dixon and P. S. Hynes, Chem. Commun., 2005, 4481.

24 A. G. M. Barrett and G. C. Grabowski, Chem. Rev., 1986, 86, 751.

25 Reviews concerning the asymmetric addition of nucleophiles to nitroalkenes: (a) O. M. Berner, L. Tedeschi and D. Enders, Eur. J. Org. Chem., 2002, 1877; (b) N. Krause and A. Hoffmann-Röder, Synthesis, 2001, 171; (c) M. P. Sibi and S. Manyem, Tetrahedron, 2000, 56, 8033.

26 A. E. Mattson, A. M. Zuhl, T. E. Reynolds and K. A. Scheidt, $J$. Am. Chem. Soc., 2006, 128, 4932.

27 S. H. McCooey, T. McCabe and S. J. Connon, J. Org. Chem., 2006, 71, 7494.

28 G. Bartoli, M. Bosco, A. Carlone, M. Locatelli, A. Mazzanti, L. Sambri and P. Melchiorre, Chem. Commun., 2007, 722.

29 P. S. Hynes, D. Stranges, P. A. Stupple, A. Guarna and D. J. Dixon, Org. Lett., 2007, 9, 2107.

30 T.-Y. Liu, H.-L. Cui, Q. Chai, J. Long, B.-J. Li, Y. Wu, L.-S. Ding and Y.-C. Chen, Chem. Commun., 2007, 2228.

31 J. Lubkoll and H. Wennemers, Angew. Chem., Int. Ed., 2007, 46, 6841.

32 It is unusual but not unprecedented for urea-based catalysts to outperform their thiourea analogues, for further examples see ref. $10 a$ and: (a) P. Vachal and E. N. Jacobsen, Org. Lett., 2000, 2, 867; (b) D. J. Maher and S. J. Connon, Tetrahedron Lett., 2004, 45, 1301 .

33 P. Dinér, M. Nielsen, S. Bertelsen, B. Niess and K. A. Jørgensen, Chem. Commun., 2007, 3646.

34 For an example of a crystal structure of a hydrogen bonded adduct between a urea and acetone see ref. $11 \mathrm{c}$.
35 H. Li, L. Zu, J. Wang and W. Wang, Tetrahedron Lett., 2006, 47, 3145.

36 T.-Y. Liu, R. Li, Q. Chai, J. Long, B.-J. Li, Y. Wu, L.-S. Ding and Y.-C. Chen, Chem.-Eur. J., 2007, 13, 319.

37 J. Wang, H. Li, L. Zu, W. Jiang, H. Xe, W. Duan and W. Wang, J. Am. Chem. Soc., 2006, 128, 12652.

38 C.-L. Gu, L. Liu, Y. Sui, J.-L. Zhao, D. Wang and Y.-J. Chen, Tetrahedron: Asymmetry, 2007, 18, 455.

39 M. M. Biddle, M. Lin and K. A. Scheidt, J. Am. Chem. Soc., 2007, 129, 3830.

40 It should be noted that at room temperature catalyst $\mathbf{1 8}$ was optimal, while at lower temperatures a $6^{\prime}$-substituted thioureabased cinchona alkaloid derivative introduced earlier by Hiemstra and co-workers (see ref. 62) furnished the product with higher enantioselectivity. In this instance we chose to focus on the use of $\mathbf{1 8}$ as it is the catalyst employed in the one-pot natural product synthesis.

41 J. Wang, L. Zu, H. Li, H. Xe and W. Wang, Synthesis, 2007, 2576.

42 Melchiorre and co-workers have shown that acidic carbon-based pronucleophiles add to maleimides in the presence of a thiourea substituted cinchona alkaloid catalyst, however the parent alkaloids were better catalysts in these reactions, see: G. Bartoli, M. Bosco, A. Carlone, A. Cavalli, M. Locatelli, A. Mazzanti, P. Ricci, L. Sambri and P. Melchiorre, Angew. Chem., Int. Ed., 2006, 45, 4966.

43 L. Zu, J. Wang, H. Li, H. Xe, W. Jiang and W. Wang, J. Am. Chem. Soc., 2007, 129, 1036.

44 B. Wang, F. Wu, Y. Wang, X. Liu and L. Deng, J. Am. Chem. Soc., 2007, 129, 768.

45 For a review of enamine catalysis of such reactions, see: S. SulzerMossé and A. Alexakis, Chem. Commun., 2007, 3123.

46 For a recent example detailing highly enantioselective modified cinchona alkaloid-catalysed additions of $\alpha$-cyanoacetates to vinyl sulfones, see ref. $8 d$.

47 T.-Y. Liu, J. Long, B.-J. Li, L. Jiang, R. Li, Y. Wu, L.-S. Ding and Y.-C. Chen, Org. Biomol. Chem., 2006, 4, 2097.

48 Selected seminal references see ref. 13 and: $(a)$ M. S. Sigman, P. Vachal and E. N. Jacobsen, Angew. Chem., Int. Ed., 2000, 39, 1279; (b) J. T. Su, P. Vachal and E. N. Jacobsen, Adv. Synth. Catal., 2000, 343, 197; (c) P. Vachal and E. N. Jacobsen, Org. Lett., 2000, 2, 867; (d) P. Vachal and E. N. Jacobsen, J. Am. Chem. Soc., 2002, 124, 10012; (e) A. G. Wenzel and E. N. Jacobsen, J. Am. Chem. Soc., 2002, 124, 12964; (f) A. G. Wenzel, M. P. Lalonde and E. N. Jacobsen, Synlett, 2003, 1919; $(g)$ G. D. Joly and E. N. Jacobsen, J. Am. Chem. Soc., 2004, 126, 4102; $(h)$ M. S. Taylor and E. N. Jacobsen, J. Am. Chem. Soc., 2004, 126, 10558; (i) T. Okino, S. Nakamura, T. Furukawa and Y. Takemoto, Org. Lett., 2004, 6, 625; (j) T. P. Yoon and E. N. Jacobsen, Angew. Chem., Int. Ed., 2005, 44, 466.

49 L. Bernardi, F. Fini, R. P. Herrera, A. Ricci and V. Sgarzani, Tetrahedron, 2006, 62, 375.

50 For previous reports detailing the catalysis of this reaction using chiral thiourea catalysts see refs. $48 i$ and $48 j$.

51 C. M. Bode, A. Ting and S. E. Schaus, Tetrahedron, 2006, 62, 11499.

52 For a separate computational study, which invokes a similar binding mode, see ref. 17.

53 A. L. Tillman, J. Ye and D. J. Dixon, Chem. Commun., 2006, 1191.

54 For a recent review of organocatalysed asymmetric Mannich reactions see ref. $2 a$.

55 J. Song, W. Wang and L. Deng, J. Am. Chem. Soc., 2006, 128, 6048.

56 J. Song, H.-W. Shih and L. Deng, Org. Lett., 2007, 9, 603.

57 T.-Y. Liu, H.-L. Cui, J. Long, B.-J. Li, Y. Wu, L.-S. Ding and Y.-C. Chen, J. Am. Chem. Soc., 2007, 129, 1878.

58 For examples, see: D. J. Faulkner, Nat. Prod. Rep., 2002, 1.

59 Y.-Q. Wang, J. Song, R. Hong, H. Li and L. Deng, J. Am. Chem. Soc., 2006, 128, 8156.

60 For an example where there is a strong such dependence, see: Y. Jia, J. Xie, H. Duan, L. Wang and Q. Zhou, Org. Lett., 2006, $8,1621$.

61 For examples of thiourea-catalysed enantioselective FriedelCrafts reactions between nitroalkenes and indoles $/ N$-alkyl indoles, respectively, see: (a) R. P. Herrera, V. Sgarzani, L. Bernardi 
and A. Ricci, Angew. Chem., Int. Ed., 2005, 44, 6576; (b) E. M. Fleming, T. McCabe and S. J. Connon, Tetrahedron Lett., 2006, 47, 7037 .

62 T. Marcelli, R. N. S. van der Haas, J. H. van Maarseveen and H. Hiemstra, Angew. Chem., Int. Ed., 2006, 45, 929.

63 Y. Wang, H. Li, Y.-Q. Wang, Y. Liu, B. M. Foxman and L. Deng, J. Am. Chem. Soc., 2007, 129, 6364.

64 M. Amere, M.-C. Lasne and J. Rouden, Org. Lett., 2007, 9, 2621.

65 (a) C. Bolm, A. Gerlach and C. L. Dinter, Synlett, 1999, 195; (b) C. Bolm, I. Schiffers, C. L. Dinter and A. Gerlach, J. Org. Chem., 2000, 65, 6984; (c) C. Bolm, I. Schiffers, I. Atodiresei and P. R. Hackenberger, Tetrahedron: Asymmetry, 2003, 14, 3455; (d) See also B. Rodríguez, T. Rantanen and C. Bolm, Angew. Chem., Int. Ed., 2006, 45, 6924.
66 For examples of the application of this methodology in target oriented synthesis, see: (a) A. Bernardi, D. Arosio, D. Dellavecchia and F. Micheli, Tetrahedron: Asymmetry, 1999, 10, 3403; (b) J. T. Starr, G. Koch and E. M. Carreira, J. Am. Chem. Soc., 2000, 122, 8793; (c) Z. Hameršak, I. Stipetić and A. Avdagić, Tetrahedron: Asymmetry, 2007, 18, 1481; (d) Z. Hameršak, M. Roje, A. Avdagić and V. Sunjić, Tetrahedron: Asymmetry, 2007, 18, 635.

67 Y. Chen, S.-K. Tian and L. Deng, J. Am. Chem. Soc., 2000, 122, 9542.

68 For an example of the application of this methodology in total synthesis, see: C. Choi, S. K. Tian and L. Deng, Synthesis, 2001, 1737.

69 A. Peschiulli, Y. Gun'ko and S. J. Connon, J. Org. Chem., 2008, 73, DOI: $10.1021 /$ jo071223b 